\title{
Identification of the Most Appropriate Site for the Cold Test in Molar Teeth
}

\author{
Identificación del sitio más apropiado \\ para la prueba de frío en dientes molares
}

Brenda E. Castillo-Silva MSc, PhD1; Nuria Patiño-Marín MSc, PhD²; Gabriel Alejandro Martínez-Castañón MSc, PhD2; Carlo E. Medina-Solís DDS, MS3; Norma Verónica Zavala Alonso MSc, PhD2; Daniel Silva-Herzog DDS, PhD²; Mariana Ramírez-Ortíz DDS, MSc ${ }^{4}$; Martha Alicia Laredo-Naranjo DDS, MSc ${ }^{4}$

1. Profesor Investigador, Facultad de Estomatología, Benemérita Universidad Autónoma de Puebla, México.

2. Profesor Investigador, Facultad de Estomatología, Doctorado en Ciencias Odontológicas, Universidad Autónoma de San Luis Potosí, México.

3. Profesor Investigador, Área Académica de Odontología. Instituto de Ciencias de la Salud. Universidad Autónoma del Estado de Hidalgo, México.

4. Estudiante del Doctorado en Ciencias Odontológicas, Facultad de Estomatología, Universidad Autónoma de San Luis Potosí, México.

Correspondence to: Dra. Nuria Patiño Marín -1nuriapm@gmail.com

Received: 22-V-2017

Accepted: 29-VI-2017

Published Online First: 4-VII-2017

DOl: https://doi.org/10.15517/ijds.v20i1.31353

\section{ABSTRACT}

A test frequently used to complement endodontic diagnoses is the cold test; however, in the last 20 years, authors have reported incorrect results within pulp sensitivity tests. Specifically, a high frequency of false results in posterior teeth, were found. The aim of this study was to identify the most appropriate site for the cold test in molar teeth with a need for endodontic treatment, calculating predictive values, accuracy and reproducibility. A cross-sectional study was performed, evaluating 390 subjects. A total of 152 subjects of both genders from the ages of 15-65 years old participated. The ideal standard was established by direct pulp inspection, and the cold test agent used was 1,1,1,2-tetrafluoroethane. The patients were divided into four groups in relation to the molar tooth: (1) mandibular first molar, (2) mandibular second molar, (3) maxillary first molar, and (4) maxillary second molar. 169 teeth and 676 sites were studied. (a) The most appropriate sites for cold test were the middle third of the buccal surface and cervical third of the buccal surface in the mandibular molars with the following results: Middle third of the first molar: Accuracy 0.93 , positive predictive value 0.90 and negative predictive value 0.96 . Middle third of the second molar: Accuracy 0.93, positive predictive value 1.00 and negative predictive value 0.90 . In relation to third cervical the results were: First molar: Accuracy 0.93 , positive predictive value 0.89 and negative predictive value 0.97 y second molar: Accuracy 0.93 , positive predictive value 1.00 and negative predictive value 0.90 . (b) The highest reproducibility was observed in the middle third of the buccal surface with cervical third of the buccal surface in the mandibular second molar (1.00). The most appropriate site and reproducibility of the sites are auxiliary to complement endodontic diagnose with the cold test.

CASTILLO B., PATIÑO N., MARTínEZ G., MEDINA C., ZAVALA N., SILVA D., RAMÍREZ M., LAREDO M., 2018: Identification of the Most Appropriate Site for the Cold Test in Molar Teeth.-ODOVTOS-Int. J. Dental Sc., 20-1 (January-April): 79-88. 


\title{
KEYWORDS
}

Cold test; Sites; Accuracy; Predictive values; Molar teeth.

\author{
RESUMEN
}

Una prueba frecuentemente utilizada para complementar los diagnósticos endodónticos es la prueba de frío. Sin embargo, en los últimos 20 años, los autores han reportado resultados incorrectos con las pruebas de sensibilidad pulpar. Específicamente, se ha observado una alta frecuencia de resultados falsos en dientes posteriores. El objetivo del estudio fue identificar el sitio más adecuado para la prueba de frío en dientes molares con necesidad de tratamiento endodóntico, calculando valores predictivos, exactitud y reproducibilidad. Se realizó un estudio transversal donde se evaluaron a 390 sujetos. 152 sujetos de ambos sexos de 15 a 65 años cumplieron con los criterios de inclusión. El estándar ideal que se utilizó en el estudio fue la inspección directa de pulpa en la cámara pulpar y la prueba de frío utilizada fue el 1,1,1,2-tetrafluoroetano. Los pacientes fueron divididos en cuatro grupos en relación al diente molar: (1) primer molar mandibular, (2) segundo molar mandibular, (3) primer molar maxilar, y (4) segundo molar maxilar. En el estudio se evaluaron 169 dientes con 676 sitios. (a) Los sitios más adecuados para la prueba de frío fueron el tercio medio y el tercio cervical de la superficie bucal en Ios molares mandibulares con los siguientes resultados: Tercio medio del primer molar: Exactitud 0.93, valor predictivo positivo 0.90 y valor predictivo negativo 0.96 . Tercio medio del segundo molar: Exactitud 0.93, valor predictivo positivo 1.00 y valor predictivo negativo 0.90. En relación al tercio cervical los resultados fueron: Primer molar: Exactitud 0.93 , valor predictivo positivo 0.89 y valor predictivo negativo 0,97 y segundo molar: Exactitud 0.93 , valor predictivo positivo 1.00 y valor predictivo negativo 0.90 . (b) La más alta reproducibilidad (1.00) se observó entre el tercio medio con el tercio cervical de la superficie bucal en el segundo molar inferior. El sitio más apropiado y la reproducibilidad de los sitios son auxiliares para complementar el diagnóstico endodóntico con la prueba de frío.

\section{PALABRAS CLAVE}

Prueba de frío; Sitios; Exactitud; Valores predictivos; Dientes molares.

\section{INTRODUCTION}

The diagnosis is the result of an analysis using different variables to identify the state of health of a patient and to consider possible treatment. A correct diagnosis in the clinic should be a procedural objective that is inexpensive (1-3). A test frequently used to complement endodontic diagnoses is the cold test; however, it is important to mention that in the last 20 years, authors have reported incorrect results within pulp sensitivity tests (3-8). Specifically, a high frequency of false results in posterior teeth with a need for endodontic treatment, were found (4-9). The thickness of enamel and dentin, dental and pulp anatomy, and multi-rooted teeth are some factors that influence the false results in molar teeth (49). The false positive results in a cold test in teeth with a need for endodontic treatment are the teeth with vital pulp that are incorrectly diagnosed in the cold test as necrotic pulp. The false negatives are the teeth with necrotic pulp that are incorrectly diagnosed in the cold test as vital pulp $(1,9,10)$. In order to identify a correct diagnosis of vital or necrotic pulp using the cold test, it is necessary to compare the result of the cold test with an ideal standard and then, to calculate the predictive values and accuracy. It is convenient to compare 
the ideal standard in the cold test because the ideal standard is an available and objective method to perform a clinical diagnosis (1-4, 9-11). Some authors have published that the ideal standard for determining the state of dental pulp is through a histological examination. However, to perform a histological examination, the extraction of the tooth is required and in several cases the extraction is not recommended by the clinic. Several authors have reported that in the clinic the ideal standard of a vital or necrotic pulp with a need for endodontic treatment is the direct inspection of the pulpal blood flow within the pulp chamber. The presence of bleeding indicates a vital pulp and the absence indicates pulp necrosis. When vital tissue is identified in the apices, but necrotic tissue is observed in the chamber, the tooth is diagnosed as necrotic $(2,4,9,12-16)$. When the results of the cold test are compared with the results of the ideal standard, the predictive values and the accuracy are obtained. The positive predictive value is the probability that a tooth without a sensitive response in the cold test represents a tooth with necrotic pulp. The negative predictive value is the probability that a tooth with a sensitive response in the cold test represents a tooth with vital pulp (1, $10,11,17)$. The predictive values are different from the sensitivity and specificity ones. The sensitivity indicates the ability of the ideal standard to identify teeth with necrotic pulp and the specificity indicates the ability of the ideal standard to identify teeth with vital pulp $(10,17)$. The concepts of accuracy and reproducibility are not similar. The accuracy is the correct result obtained from the cold test compared with the ideal standard (1214). The reproducibility is the ability of a test to reproduce the same result when the variable is measured twice, specifically in two different sites of the tooth (13). The gender, psychological and biological factors, age of the tooth, clinical pathologies in the tooth (extensive caries, reduced pulp chamber, a periodontal pocket, enamel loss, pulp necrosis) and the placement sites of the test in the tooth are associated with false results in a pulpal sensitivity test $(1,18-21)$. Therefore, the objective of this study was to identify the most appropriate site for the cold test in molar teeth with a need for endodontic treatment, calculating predictive values, accuracy and reproducibility.

\section{MATERIALS AND METHODS}

Three hundred and ninety patients referred for endodontic care were evaluated in the Clinic of Dentistry at San Luis Potosí University in Mexico. Following the ethical principles of Helsinki's declaration, an informed and voluntary written consent was obtained before beginning the crosssectional study (December 2012 to December 2016). The study was approved by the Research Ethics Committee of Faculty of Dentistry, San Luis Potosí University, San Luis Potosí, SLP, Mexico. A total of 152 subjects of both genders aged between 17 and 65 years met the following inclusion criteria: Subjects without diagnosed systemic diseases, without medication 24 hours before starting the study, and had molars with a need for endodontic treatment. Exclusion criteria included: orthodontic treatment or trauma (within the last 6 months), restorations at the sites evaluated, cavity access, calcified root canals, and incomplete root formation $(1,2,9)$. The patients were divided into four groups in relation to the molar tooth with a need for endodontic treatment: Group 1. Mandibular first molar, Group 2. Mandibular second molar, Group 3. Maxillary first molar and Group 4. Maxillary second molar. All participants were evaluated with the following protocol.

\section{EXAMINATION AND DIAGNOSTIC PROCEDURES}

An investigator recorded the subject's medical and dental history using the following criteria: (a) principal complaint (onset, duration, frequency, intensity, and location of pain), (b) conducted a clinical examination (coronal evaluation for caries, restorations, and enamel loss), (c) periodontal evaluation, and (d) radiographic analysis (size of 
the pulp chamber and root canals, radiolucent lesions, and thickened periodontal ligament).

\section{COLD PULPAL TESTING}

Each patient was instructed to raise one hand when they experienced a sensation during cold testing and lower his or her hand when the response disappeared (1). The teeth were isolated with cotton rolls and dried with cotton gauze (22, 23). Two researchers applied the cold sensibility test and were blinded to dental history, clinical signs and symptoms, periodontal and radiographic findings. One of the investigators recorded the responses and the response times in seconds without identifying the placement site of the test (blind to the application site) with the following procedure: (A) First time (FT) was the number of seconds from the application of the cold stimulus until the participant experienced a sensation and raised a hand (response). (B) Second time (ST) was the number of seconds following the removal of the stimulus until the sensation disappeared (recovery) (1). The second investigator applied the test in the different sites without identifying the response of the test in seconds (blind in the response of the test in seconds) (5). Each tooth was evaluated at the following four sites: (1) In the center of the middle third of the buccal surface (MTBS), (2) In the center of the cervical third of the buccal surface (CTBS), (3) In the center of the middle third of the lingual surface (MTLS), and (4) In the center of the mesio-buccal cusp surface (MBCS). The second investigator allowed 5 minutes between the evaluation of one site and another site to ensure recovery of the pulp $(1,3)$. A refrigerant spray (1,1,1,2-tetrafluoroethane) (Hygenic Endo-Ice Green [Endo-Ice]; Coltene Whaledent, Cuyahoga Falls, $\mathrm{OH})(1,6,9)$ was placed on a no. 2 cotton pledget and was applied onto the crown of the tooth for 25 seconds or until the subject raised a hand.
Ideal Standard. After completing the tests, a researcher anesthetized the patient with $2 \%$ lidocaine and 1:100,000 diluted epinephrine. The ideal standard of pulp status was recorded by observing the bleeding within the pulp chamber in cases of vital pulp, or the absence of bleeding, which represents a necrotic pulp. The presence of vital tissue in the apice and of necrotic tissue in the chamber was diagnosed as necrotic pulp (2-4, 9). All participants completed the treatment.

\section{STATISTICAL ANALYSIS}

Mean, standard deviation, rank, frequency, percentage, sensitivity, specificity, accuracy, positive predictive value, and negative predictive value were calculated. The reproducibility was determined with the Kappa Simple test (Cohen). Spearman rho test was calculated to identify correlations between the FT of two sites and the ST of two sites in the tooth. The analyses were executed using Stata statistical software (version 11; StataCorp, College Station, TX).

\section{RESULTS}

From the 390 patients evaluated, 152 met the selection criteria: 89 were females (59\%) and 63 males (41\%) between the range of 17 to 65 years (36 \pm 13.5$) ; 169$ teeth and 676 sites were studied. Table 1 shows the clinical evaluation of mandibular and maxillary molar teeth with vital and necrotic pulp diagnosed with the ideal standard. The most frequently seen tooth was the mandibular first molar $(n=63)$. The vital pulp was the most common diagnosis with the ideal standard $(58 \%, n=94$ teeth) and dental caries was the most frequent pathology $(n=100)$. The sensitivity, specificity, predictive values, accuracy, false-positives, and false-negatives in the four sites of the four groups are shown in Table 2. The highest accuracy occurred in the first and second 
mandibular molars (0.93) in the sites MTBS (first molar, PPV 0.90 and NPV 0.96; second molar, PPV 1.00 and NPV 0.90) and CTBS (first molar, PPV 0.89 and NPV 0.97; second molar, PPV 1.00 and NPV 0.90). The lowest accuracy $(0.70)$ was observed in the maxillary second molar in the site MBCS (PPV of 0.57 and NPV of 0.84). Regarding false positives and negatives, the highest values of false positives were observed in the MBCS of the maxillary first molar (frequency $=12$ ) and the highest false negatives were observed in the MBCS of the mandibular first molar (frequency $=4$ ). Table 3 shows the reproducibility between the sites in the groups. The value of higher reproducibility between sites was 1.00 (MTBS vs. CTBS) in the mandibular second molar with a correlation $>0.80$ (rho) and $p<0.05$ in the FT and ST in vital pulps. Other correlations were not observed between the times in the sites. The lowest reproducibility was 0.35 in the maxillary first molar between the sites MTBS vs. MBCS. Table 4 shows the time of response and recovery in seconds of the test in the four sites; the fastest FT (response) was at the cervical third of the buccal surface site with a mean of 2.2 (rank 1-5) in the maxillary first molar, and the fastest ST (recovery) was at the middle third lingual surface site with a mean of 3.7 (rank $1-10)$ in the maxillary second molar.

Table 1. Clinical evaluation in mandibular and maxillary molar teeth diagnosed with the ideal standard with vital and necrotic pulp.

\begin{tabular}{|c|c|c|c|c|c|c|c|c|c|}
\hline \multirow{2}{*}{$\begin{array}{c}\text { Tooth type } \\
\text { Diagnosis } \\
\text { (Ideal standard) }\end{array}$} & \multicolumn{2}{|c|}{$\begin{array}{l}\text { Mandibular first molar } \\
\qquad(\mathrm{n}=63)\end{array}$} & \multicolumn{2}{|c|}{$\begin{array}{l}\text { Maxillary first molar } \\
\quad(n=46)\end{array}$} & \multicolumn{2}{|c|}{$\begin{array}{l}\text { Mandibular second molar } \\
\qquad(\mathrm{n}=33)\end{array}$} & \multicolumn{3}{|c|}{$\begin{array}{l}\text { Maxillary second molar } \\
\qquad(\mathrm{n}=27)\end{array}$} \\
\hline & $\begin{array}{l}\text { Vital } \\
\text { pulp }\end{array}$ & $\begin{array}{l}\text { Necrotic } \\
\text { pulp }\end{array}$ & $\begin{array}{l}\text { Vital } \\
\text { pulp }\end{array}$ & $\begin{array}{l}\text { Necrotic } \\
\text { pulp }\end{array}$ & $\begin{array}{l}\text { Vital } \\
\text { pulp }\end{array}$ & $\begin{array}{l}\text { Necrotic } \\
\text { pulp }\end{array}$ & $\begin{array}{l}\text { Vital } \\
\text { pulp }\end{array}$ & $\begin{array}{l}\text { Necrotic } \\
\text { pulp }\end{array}$ & \\
\hline Clinical Evaluation & \multicolumn{8}{|c|}{ Frequency (\%) } & Total \\
\hline Caries & $19(30)$ & $19(30)$ & $14(30)$ & $14(30)$ & $10(31)$ & $9(27)$ & $10(37)$ & $5(19)$ & 100 \\
\hline Caries and restoration & $8(13)$ & $5 \quad(8)$ & $4(9)$ & $3(7)$ & $5(15)$ & 1 (3) & $5(19)$ & $3(11)$ & 34 \\
\hline Restoration & $7(11)$ & $4 \quad(6)$ & $4(9)$ & $6(13)$ & 3 (9) & 3 (9) & $2(7)$ & $2(7)$ & 31 \\
\hline Enamel loss & 1 (2) & $0 \quad(0)$ & $0(0)$ & 1 (2) & $2(6)$ & 0 & 0 & $0(0)$ & 4 \\
\hline Total & $35(56)$ & $28 \quad(44)$ & $22(48)$ & $24(52)$ & $20(61)$ & $13(39)$ & $17(63)$ & $10(37)$ & 169 \\
\hline
\end{tabular}


Table 2. Sensitivity, Specificity, Predictive values, Accuracy, False-positives, and False-negatives in the four sites of the groups.

\begin{tabular}{lccccccc}
\hline \multicolumn{1}{c}{ Tooth type / Sites } & Sensitivity & Specificity & PPV & NPV & Accuracy & FP & FN \\
\cline { 2 - 5 } Mandibular first molar & & & & & & & \\
MTBS & 0.96 & 0.91 & 0.90 & 0.96 & 0.93 & 3 & 1 \\
CTBS & 0.96 & 0.91 & 0.89 & 0.97 & 0.93 & 3 & 1 \\
MTLS & 0.96 & 0.96 & 0.75 & 0.96 & 0.84 & 9 & 1 \\
MBCS & 0.85 & 0.74 & 0.72 & 0.86 & 0.79 & 9 & 4 \\
Maxillary first molar & & & & & & & \\
MTBS & 1.00 & 0.81 & 0.85 & 1.00 & 0.91 & 4 & 0 \\
CTBS & 1.00 & 0.81 & 0.85 & 1.00 & 0.91 & 4 & 0 \\
MTLS & 1.00 & 0.77 & 0.82 & 1.00 & 0.89 & 5 & 0 \\
MBCS & 0.95 & 0.45 & 0.65 & 0.90 & 0.71 & 12 & 1 \\
Mandibular second molar & & & & & & & \\
MTBS & 0.84 & 1.00 & 1.00 & 0.90 & 0.93 & 0 & 2 \\
CTBS & 0.84 & 1.00 & 1.00 & 0.90 & 0.93 & 0 & 2 \\
MTLS & 0.85 & 1.00 & 1.00 & 0.81 & 0.90 & 0 & 3 \\
MBCS & 0.84 & 0.80 & 0.73 & 0.88 & 0.81 & 4 & 2 \\
Maxillary second molar & & & & & & & \\
MTBS & 0.90 & 0.76 & 0.69 & 0.92 & 0.81 & 4 & 1 \\
CTBS & 0.90 & 0.70 & 0.64 & 0.92 & 0.77 & 5 & 1 \\
MTLS & 0.80 & 0.70 & 0.61 & 0.93 & 0.74 & 5 & 2 \\
MBCS & 0.80 & 0.64 & 0.57 & 0.84 & 0.70 & 6 & 2 \\
\hline
\end{tabular}

MTBS, site middle third of the buccal surface; CTBS, site cervical third of the buccal surface; MTLS, site middle third of the lingual surface; MBCS, site mesio-buccal cusp surface; PPV, positive predictive values; NPV, negative predictive values; FP, frequency of false positives; and FN, frequency of false negatives. Prevalence: Mandibular first molar 44\%, maxillary first molar 52\%, mandibular second molar 39\%, and maxillary second molar $37 \%$.

Table 3. Reproducibility between the sites in the groups of study.

\begin{tabular}{lcccccc}
\hline $\begin{array}{c}\text { Comparison between } \\
\text { sites }\end{array}$ & $\begin{array}{c}\text { MTBS } \\
\text { vs. } \\
\text { CTBS }\end{array}$ & $\begin{array}{c}\text { MTBS } \\
\text { vs. } \\
\text { MTLS }\end{array}$ & $\begin{array}{c}\text { MTBS } \\
\text { vs. } \\
\text { MBCS }\end{array}$ & $\begin{array}{c}\text { CTBS } \\
\text { vs. } \\
\text { MTLS } \\
\text { *Reproducibility }\end{array}$ & $\begin{array}{c}\text { CTBS } \\
\text { vs. } \\
\text { MBCS }\end{array}$ & $\begin{array}{c}\text { MTLS } \\
\text { vs. } \\
\text { MBCS }\end{array}$ \\
$\begin{array}{l}\text { Mandibular first molar } \\
\text { Maxillary first molar }\end{array}$ & 0.80 & 0.80 & 0.52 & 0.69 & 0.58 & 0.46 \\
Mandibular second molar & 0.70 & 0.66 & 0.35 & 0.89 & 0.46 & 0.50 \\
Maxillary second molar & $1.00^{\star \star}$ & 0.68 & 0.48 & 0.68 & 0.48 & 0.44 \\
\hline
\end{tabular}

MTBS, site middle third of the buccal surface; CTBS, site cervical third of the buccal surface; MTLS, site middle third of the lingual surface; MBCS, site mesio-buccal cusp surface. ${ }^{*}$ Test of Kappa (Cohen). ${ }^{*}$ Correlation of Spearman (rho $>0.80$ and $\left.p<0.05\right)$ in the first time and second time (seconds). 
Table 4. Results in seconds of the test in the four sites with vital pulp diagnosed with the ideal standard in the groups of study.

\begin{tabular}{lcccc}
\hline \multicolumn{1}{c}{ Sites } & $\begin{array}{c}\text { Middle third of the } \\
\text { buccal surface }\end{array}$ & $\begin{array}{c}\text { Cervical third of the } \\
\text { buccal surface }\end{array}$ & $\begin{array}{c}\text { Middle third of the } \\
\text { lingual surface }\end{array}$ & Mesio-buccal cusp \\
\hline \multicolumn{1}{c}{$\begin{array}{c}\text { Tooth type } \\
\text { Mandibular first molar }\end{array}$} & \multicolumn{2}{c}{ Mean \pm SD (Rank) } \\
FT & $3.2 \pm 3.4(1-15)$ & $3.4 \pm 3.8(1-15)$ & $3.9 \pm 3.0(1-11)$ & $4.7 \pm 4.1(1-19)$ \\
ST & $4.9 \pm 2.8(1-10)$ & $5.1 \pm 3.0(1-12)$ & $4.2 \pm 4.1(1-18)$ & $4.2 \pm 3.9(1-18)$ \\
Maxillary first molar & & & & \\
FT & $2.5 \pm 1.8(1-8)$ & $2.2 \pm 1.2(1-5)$ & $3.3 \pm 2.1(1-8)$ & $3.7 \pm 2.1 \quad(1-8)$ \\
ST & $5.0 \pm 3.1(1-12)$ & $7.3 \pm 4.2(3-20)$ & $6.3 \pm 4.0(1-20)$ & $5.1 \pm 2.6(2-9)$ \\
Mandibular second molar & & & & \\
FT & $3.0 \pm 2.4(1-11)$ & $2.9 \pm 2.4(1-11)$ & $4.3 \pm 3.6(1-13)$ & $5.6 \pm 5.6(1-16)$ \\
ST & $5.6 \pm 3.1(1-11)$ & $6.2 \pm 4.3(1-15)$ & $5.5 \pm 3.7(1-14)$ & $5.4 \pm 3.4(1-12)$ \\
Maxillary second molar & & & & \\
FT & $2.8 \pm 2.4(1-10)$ & $2.5 \pm 2.6(1-10)$ & $4.4 \pm 3.6(1-12)$ & $6.0 \pm 5.2(1-15)$ \\
ST & $4.8 \pm 1.7(3-8)$ & $5.3 \pm 2.0(2-8)$ & $3.7 \pm 2.4(1-10)$ & $3.8 \pm 2.8(1-9)$ \\
\hline
\end{tabular}

SD, standard deviation; FT, first time in seconds; ST, second time in seconds.

\section{DISCUSSION}

Over the last years, a higher frequency of incorrect diagnoses in pulpal sensitivity tests was reported in molar teeth, therefore, it is necessary to continue with different studies to decrease the high frequency of false results $(1,4-8)$. The objective of this study was to identify the most appropriate site for the cold test in molar teeth with a need for endodontic treatment calculating predictive values, the accuracy, and the reproducibility. In the present study, four sites were evaluated in molar teeth: (1) CTBS, because it is the closest to the pulp chamber and the thinnest aspect of the enamel $(1,5,6)$; (2) MTBS, the site used by most of the studies because of the accuracy and because researchers have reported that it presents the least resistance in electrical testing $(1,7,8$, 22, 24); (3) MTLS, a site that has been evaluated with electrical testing because of its proximity to the pulp horns (24, 25); and (4) MBCS, because the first molar (maxillary and mandible) was the site that responded at the lowest threshold in the electrical test (25). The predictive values, accuracy and reproducibility were calculated to identify the most appropriate site for the cold test. In order to use the previous calculations an ideal standard was necessary. In the clinic the ideal standard of a vital or necrotic pulp diagnosis is the direct inspection of the pulpal blood flow within the pulp chamber. The microcirculation and nerve fibers are two components of pulpal inflammation. The microcirculation within the dental pulp causes an inflammatory response as part of a complex defensive mechanism. This inflammatory reaction induces vasodilatation. On the other hand, any increase in blood flow and vascular permeability can cause major changes in the pressure inside the pulp chamber, which may compress blood vessels and lead to a decrease in the pulp flow. In terms of the nerve fibers within the pulp vascularized by the blood flow, nerve bundles diverge and branch out towards the pulp-dentin border. Nerve divergence continues until each bundle loses its integrity, and smaller fiber groups travel towards the dentin. The nerve fibers transmit the nerve impulse causing 
a positive response in the test using the cold stimulus. The inflammatory response including the pulp blood flow and nerve fibers within the pulp chamber represents a positive response in the cold test, and the absence of blood flow and nerve fibers, represent a negative response $(15,16)$. It is necessary to indicate that the direct inspection of the pulpal blood flow is the ideal standard for teeth with vital and necrotic pulp, without specifying the state of pulp inflammation. This ideal standard commonly should not be considered in teeth with vital pulp without inflammation because the direct inspection of the camera is not justified. It could be considered by the clinic, but only in very specific cases. All the teeth included in this study required endodontic treatment because of the presence of pulpitis; therefore, the direct inspection of the pulpal blood flow was observed. In relation to predictive values, the prevalence of necrotic pulps must be considered because the values are affected by the prevalence. In this study the prevalence of necrotic pulps was $44 \%$ in the mandibular first molar, $52 \%$ in the maxillary first molar, 39\% in the mandibular second molar and $37 \%$ in the maxillary second molar $(1,3,4-11$, $17,22-25)$. In the results, it was noted that the sites with the highest accuracy in the mandibular molars and the maxillary first molar were the MTBS and CTBS (values of 0.77 to 0.93 ) with predictive values $\geq 0.80$ (1.00 to 0.85$)$. These results are consistent with several other studies $(1,3,4)$. In the maxillary second molar the PPV was 0.69 to the site MTBS and 0.64 to the CTBS. This might be due to the greater thickness of enamel in the upper molars, particularly in the second maxillary molar, a factor that could isolate the cold stimulus (26). In relation to incorrect diagnoses, the highest frequency of false responses was at the MBCS, particularly in the first molars, both maxillary $(\mathrm{n}=$ 12) and mandibular $(n=4)$. Our findings contrast with Lin et al., whose study included electric testing in first molars. The best site was the mesio-buccal cusp tip because of its highest concentration of neural elements in pulp horns (25). A possible explanation of why our results are inconsistent with Lin et al., might be the different mechanisms in both tests (cold vs. electric), the methodology of the study, and analysis of the data. Some possible factors related with false responses in the pulp sensitivity tests are: multi-rooted teeth, clinical characteristics of the tooth (caries, smaller pulp chambers, the pocket and periodontal attachment loss, enamel loss, necrotic teeth, and asymptomatic teeth), and the application of the test, including the placement site $(1,3-8,25)$. On the other hand, the reproducibility in the diagnosis is the ability to reproduce the same results in two different sites of a tooth. The reproducibility can confirm a diagnosis or create a new diagnosis in another site (13). The most exact sites (0.93) in this study were the MTBS and CTBS with a reproducibility of 1.00 (MTBS vs. CTBS) in the mandibular second molar. Therefore, the diagnosis can be made from the sites MTBS or CTBS with the test because both were exact and reproducible. In relation to response times in the mandibular second molar the FT was of 2.9-3.0 (mean) and the ST was of 5.6-6.2 (mean) seconds.

Approximately $50 \%$ of subjects with vital pulp were included in the study to correctly identify predictive values, accuracy and reproducibility. With the above, it can not calculate an association between the response of the cold test and the type of tooth or the site in tooth.

The results of this study can be used as an auxiliary for pulp sensitivity tests. It is recommended to undergo further studies on teeth with reversible, irreversible pulpitis and healthy pulps focused on the endodontic clinic practice.

\section{CONCLUSION}

The most appropriate sites for cold tests were the MTBS and CTBS with a reproducibility 
of 1.00 between sites (MTBS vs. CTBS) in the mandibular second molar with a need for endodontic treatment.

\section{ACKNOWLEDGMENTS}

Fondo de Apoyo a la Investigación. Universidad Autónoma de San Luis Potosí. FAlUASLP.

\section{REFERENCES}

1. Villa-Chávez C. E., Patiño-Marín N., Loyola-Rodríguez J. P., Zavala-Alonso N. V., Martínez-Castañón G. A., Medina-Solís C. E. Predictive values of thermal and electrical dental pulp tests: a clinical study. J Endod. 2013; 39 (8): 965-969.

2. Dastmalchi N., Jafarzadeh H., Moradi S. Comparison of the efficacy of a custom-made pulse oximeter probe with digital electric pulp tester, cold spray, and rubber cup for assessing pulp vitality. J Endod. 2012; 38 (9): 1182-1186.

3. Gopikrishna V., Tinagupta K., Kandaswamy D. Comparison of electrical, thermal, and pulse oximetry methods for assessing pulp vitality in recently traumatized teeth. J Endod. 2007; 33 (5): 531-535.

4. Jespersen J. J., Hellstein J., Williamson A., Johnson W. T., Qian F. Evaluation of Dental Pulp Sensibility Tests in a Clinical Setting. J Endod. 2014; 40 (3): 351-354.

5. Peters D. D., Baumgartner J. C., Lorton L. Adult pulpal diagnosis. I. Evaluation of the positive and negative responses to cold and electrical pulp tests. J Endod. 1994; 20 (10): 506-511.

6. Chen E., Abbott P. V. Evaluation of accuracy, reliability, and repeatability of five dental pulp tests. J Endod. 2011; 37 (12): 619-1623.

7. Farac R. V., Morgental R. D., Lima RKDP, Tiberio D, dos Santos MTBR. Pulp sensibility test in elderly patients. Gerodontology. 2012; 29 (2): 135-139.

8. Jones V. R., Rivera E. M., Walton R. E. Comparison of carbon dioxide versus refrigerant spray to determine pulpal responsiveness. J Endod. 2002; 28 (7): 531-533.

9. Weisleder R., Yamauchi S., Caplan D., Trope M., Teixeira F. The validity of pulp testing a clinical study. J Am Dent Assoc. 2009;140 (8):1013-1017.

10. Altman D. G., Bland J. M. Diagnostic tests. 1: sensitivity and specificity. BMJ. 1994; 308 (6943): 1552.

11. Safari S., Baratloo A., Elfil M., Negida A. Evidence based emergency medicine part 2: positive and negative predictive values of diagnostic tests. Emerg (Tehran). 2015; 3 (3): 87-88.

12. Gopikrishna V., Tinagupta K., Kandaswamy D. Evaluation of efficacy of a new custommade pulse oximeter dental probe in comparison with the electrical and thermal tests for assessing pulp vitality. J Endod. 2007; 33 (4): 411-414.

13. Banoo S., Bell D., Bossuyt P., Herring A., Mabey D., Poole F., et al. Evaluation of diagnostic tests for infectious diseases: general principles. Nat Rev Microbiol. 2010; 8 (12): S17-S29.

14. Petersson K., Söderström C., Kiani-Anaraki M., Lévy G. Evaluation of the ability of thermal and electrical tests to register pulp vitality. Endod Dent Traumatol. 1999; 15 (3): 127-131.

15. Alghaithy R. A., Qualtrough A. J. Pulp sensibility and vitality tests for diagnosing pulpal health in permanent teeth: a critical review. Int Endod J. 2017; 50 (2): 135-142.

16. Cartagena A. F., Parreiras S. O., Loguercio A. D., Reis A., Campanha N. H. In-office bleaching effects on the pulp flow and tooth sensitivity - case series. Braz Oral Res. 2015; 29 (1): S1806-83242015000100223. 
17. Altman D. G., Bland J. M. Diagnostic tests 2: predictive values. BMJ. 1994;309(6947): 102.

18. Davies AL, Rawlinson A. A comparison between two electric vitality testers and ethyl chloride with special reference to a newly available device. Int Endod J. 1988; 21 (5): 320-326.

19. Lilja J. Innervation of different parts of the predentin and dentin in young human premolars. Acta Odontol Scand. 1979; 37 (6): 339-346.

20. Rutsatz C., Baumhardt S. G., Feldens C. A., Rösing C. K., Grazziotin-Soares R., Barletta F. B. Response of pulp sensibility test is strongly influenced by periodontal attachment loss and gingival recession. J Endod. 2012; 38 (5): 580-583.

21. Peters D. D., Baumgartner J. C., Lorton L. Adult pulpal diagnosis. I. Evaluation of the positive and negative responses to cold and electrical pulp tests. J Endod. 1994; 20 (10): 506-511.

22. Fuss Z., Trowbridge H. O., Bender I., Rickoff B. Assessment of reliability of electrical and thermal pulp testing agents. J Endod. 1986;12 (7): 301-305.

23. Al-Salman T. H. The effects of type of tooth and the placement site of electrode on the electrical pulp testing of the anterior teeth. Al-Rafidain Dent J. 2005; 5 (2): 97-102.

24. Jacobson J. J. Probe placement during electric pulp-testing procedures. Oral Surg Oral Med Oral Pathol. 1984; 58 (2): 242-247.

25. Lin J., Chandler N., Purton D., Monteith B. Appropriate Electrode Placement Site for Electric Pulp Testing First Molar Teeth. J Endod. 2007; 33 (11): 1296-1298.

26. Macho G. A., Berner ME. Enamel thickness of human maxillary molars reconsidered. Am J Phys Anthropol. 1993; 92 (2): 189-200. 